$1-1-1960$

\title{
The relation of knowledge to adoption of recommended practices
}

Leonard Marion Sizer

Porter, Ward F.

Follow this and additional works at: https://researchrepository.wvu.edu/ wv_agricultural_and_forestry_experiment_station_bulletins

\section{Digital Commons Citation}

Sizer, Leonard Marion and Porter, Ward F., "The relation of knowledge to adoption of recommended practices" (1960). West Virginia Agricultural and Forestry Experiment Station Bulletins. 446.

https://researchrepository.wvu.edu/wv_agricultural_and_forestry_experiment_station_bulletins/422 @ WVU. It has been accepted for inclusion in West Virginia Agricultural and Forestry Experiment Station Bulletins by an authorized administrator of The Research Repository @WVU. For more information, please contact ian.harmon@mail.wvu.edu. 


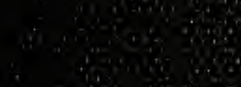

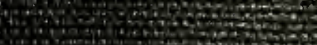


Digitized by the Internet Archive in 2010 with funding from

Lyrasis Members and Sloan Foundation 


\section{Bulletin 446}

The Relation of Knowledge To Adoption of Recommended Practices 


\section{THE AUTHORS}

Leonard M. Sizer is Associate Rural Sociologist in the Agricultural Experiment Station and Associate Professor of Rural Sociology in the College of Agriculture, Forestry, and Home Economics. Ward F. Porter is Extension Analyst, Teaching Methods Research Branch, Division of Research and Training, Federal Extension Service, United States Department of Agriculture.

WEST VIRGINIA UNIVERSITY

Agricultural Experiment Station

College of Agriculture, Forestry, and Home Economics

A. H. Vanlandingham, Director

MORGANTOWN 


\section{The Relation of Knowledge To Adoption of Recommended Practices}

LEONARD M. SIZER and WARD F. PORTER

IFFUSION research has contributed to our understanding of the difficulties in the communication process. Such research has shown that a significant number of farmers fail to adopt certain practices essential to efficient commercialized farming. It has become increasingly clear that it is necessary to probe in depth the reasons underlying failure to apply recommended practices. Such knowledge is desirable to assist American farmers in efficiency of operations.

One factor affecting a farmer's adoption of a recommended practice is his degree of knowledge of the practice involved. This variable requires added attention to obtain more accurate estimates of the farmer's understanding of complicated farming procedures.

The Federal Extension Service recently has been engaged in a study of cotton production in nine Southern States. ${ }^{1}$ Analysis of the data revealed marked differentials in yields although recommended practices had ostensibly been followed. Since there had been some control over variables recognized as affecting yields, the data suggested that the cotton farmers were not as well informed about the recommended practices as had been assumed. The application of spray as a control measure had not been adequate. It seemed that many of the farmers did not know what, when, and how to spray. ${ }^{2}$

The often-quoted testimony that a respondent already knows more than he demonstrates in practice reflects a widely-held assumption which may be erroneous.

Still another promising area in diffusion research is the degree of adoption of certain practices which involve interrelated steps and procedures. Most practices necessitate precision in one or more respects. This may specify definite timing, particular materials, or tightly lockedstep behavior. Although depth of understanding may not need to be

${ }^{1}$ Raudabaugh, J. Neil, A Study of the Cotton Production Improvement Program in Nine Southern States, U.S.D.A., Extension Service Circular 515, Dec. 1957.

${ }^{2}$ Ibid, Table 26. Cotton fields were scouted to determine the need for insecticides by the farmers themselves and also by the County Agent and the farmers jointly. Forty-three percent of the farmers who had the technical assistance of the County Agent were in the high yield group. Only 23 percent of those who scouted their own fields without the Agent's assistance had comparable yields. The Agent's greater knowledge appeared to be decisive. 
complete, an appreciation of the results to be obtained and the critical nature of the prescriptions are required. Since a recommended practice is usually a complex of interrelated steps and procedures in which degree of preciseness is a factor there are obvious difficulties inherent in determining the extent to which all of the procedure recommendations are followed. Accepting inadequate evidence of adoption may foster spurious assumptions about the success of action programs involved.

Furthermore, to the extent that adoption is only partial, a farm operator may achieve results below his expectations. ${ }^{3}$ This may cause him to reject the practice entirely, with the consequent development of negative attitudes. The problems of administering an effective educational-action program thereby are intensified.

This bulletin is concerned with the relationship of knowledge about certain farm practices to other social-economic variables and the relationship of these variables to the adoption of recommended practices. One of the hypotheses to be tested was the relationship of the degree of knowledge to the degree of adoption. The assumption that there is a relationship would occasion little debate. However, the investigation of this hypothesis requires the objective determination of the responclent's knowledge and understanding of selected practice recommendations, as well as the degree to which these recommendations have been followed. Such a determination may require a more comprehensive and detailed accounting of what a respondent knows and does than many of us have heretofore attempted. ${ }^{4}$

\section{The Data}

Pocahontas County was chosen as a sample area to study these relationships because on a number of selected items it seemed to be representative of State economic Area V, one of the important agricultural areas of the State.

The following seven agronomic and livestock practices were selected from those recommended by Agricultural Extension Service: clipping permanent pasture, use of hybrid seed corn, spraying beef cattle, spraying sheep, feeding phenothiazine to sheep, housing the laying flock in winter, and separating chicks from hens.

Data about current practices and about knowledge of recommendations concerning these practices, along with social and economic data,

${ }^{3}$ For example, some of the respondents in this study had rejected hybrid corn after a trial period because the corn had matured too late in the year. Presumably, they had used varieties that were not adapted to their area.

${ }^{5}$ Evidence of increased interest in this particular problem is suggested in Appendix 1. 
were collected from a 20 percent probability-area-sample of farm operators. Appendix 2 gives the sequence of questions regarding mowable pasture. This sequence illustrates the pattern used for all practices.

In light of the minor economic importance of certain of the crops or animal holdings, relatively lenient criteria ${ }^{5}$ were used for crediting adoption of recommended practices.

\section{Measurements}

It was necessary to develop several techniques of measurement for the analysis of the data. These are described below.

The degree-of-adoption score is a value assigned to each operator based upon the number of recommended practices he had adopted from among those for which he had the requisite crops or animals. This score is the result of dividing the number of recommended practices adopted by the number of practices for which he has the requisite crops or animals and multiplying the quotient by one hundred.

A practice-knowledge score is a value assigned to each operator for each practice based upon his knowledge of each of the seven recommended practices. The score of each operator for each practice was assigned as follows: 0 for no knowledge, 1 for vague knowledge, 2 for an intermediate level of knowledge, and 3 for complete and accurate knowledge. The assigning of practice-knowledge scores was a preliminary step in deriving degree-of-knowledge scores. A degree-of-knowledge score $^{\beta}$ is a value assigned to each operator based upon his knowledge of the seven recommended practices for which he had the requisite crops or animals. The score is the sum of the practice-knowledge scores for which he had the requisite crops or animals divided by three times the number of recommended practices represented and the quotient multiplied by one hundred.

Each operator was assigned a level-of-living score. This consisted of the total number of items he possessed from among the following; automobile, bath, electricity, freezer, magazine (non-farm), refrigerator. stove (gas or electric), telephone, toilet (inside), truck, washer (powered), running water, and an eighth grade education. In cases where individuals reported one or more years of high school education, two points were added instead of one.

\footnotetext{
${ }^{5}$ For example, extension recommendations entail mowing permanent pastures twice during a season at specified times. Adoption was credited in this study if the permanent pasture had been mown during the previous season.

${ }^{6} \mathrm{~A}$ second set of degree-of-knowledge scores was assigned to each operator based upon all seven practices without regard to the operator's possession of the requisite crops or animals. This set of degree-of-knowledge scores was compared with the previously assigned degree-of-knowledge scores.

This second set of degree-of-knowledge scores was significantly less than the f1rst set. This indicated that the knowledge of the West Virginia farm operator was functional.
} 
Each operator was assigned a participation score based on the sum of his activities in organizations. Four points were for office held, three for committee membership, two for active membership, and one for inactive membership.

Each operator was assigned an isolation score according to the location of his home in relation to a hard-top or an improved road. Each location was scored as follows: 1 point, if on a hard-top road; 2, if on an improved road; 3 , if less than 1 mile from an improved road or hard-top road; 4 , if 1.0 to 2.9 miles from either type road; 5 , if 3.0 to 4.9 miles from either type road; $6,5.0$ or more miles from either.

\section{The Analysis of the Results}

Table 1 shows the intercorrelations between degree-of-adoption scores, degree-of-knowledge scores, and nine other social and economic variables. It is recognized in computing the various product moment correlations that not all of the assumptions which are requisite to its use have been strictly observed, particularily the suggested number of categories. It was felt, however, that the use of the intercorrelations, together with partial and multiple correlations, would be the best approach to the analysis of the data.

Table 2 shows multiple and partial correlation coefficients which were calculated through the use of the intercorrelation in Table 1. The multiple correlation coefficients were calculated to study the magnitude of the influence of additional factors upon the relationship between degree of adoption and degree of knowledge. The partial correlation coefficient were calculated to study the relationship be. tween degree of adoption and degree of knowledge, while the influences of other variables were held constant.

\section{Discussion}

The relationship between degree-of-adoption and degree-of-knowledge scores is indicated in Table 1 . The product moment correlation is .398. Statistically a value of this size is very highly significant. This $r$ value $^{7}$ is not significantly greater than the $r$ value between degree-ofadoption and level-of-living scores or between degree-of-adoption and participation scores. There is, however, a greater $r$ value between degreeof-adoption and degree-of-knowledge scores than between degree-of-adoption scores and any of the remaining seven variables used in the study.

${ }^{7} \mathrm{~A}$ difference of $\mathrm{r}$ values of .124 is significant at the .05 level of confidence. 


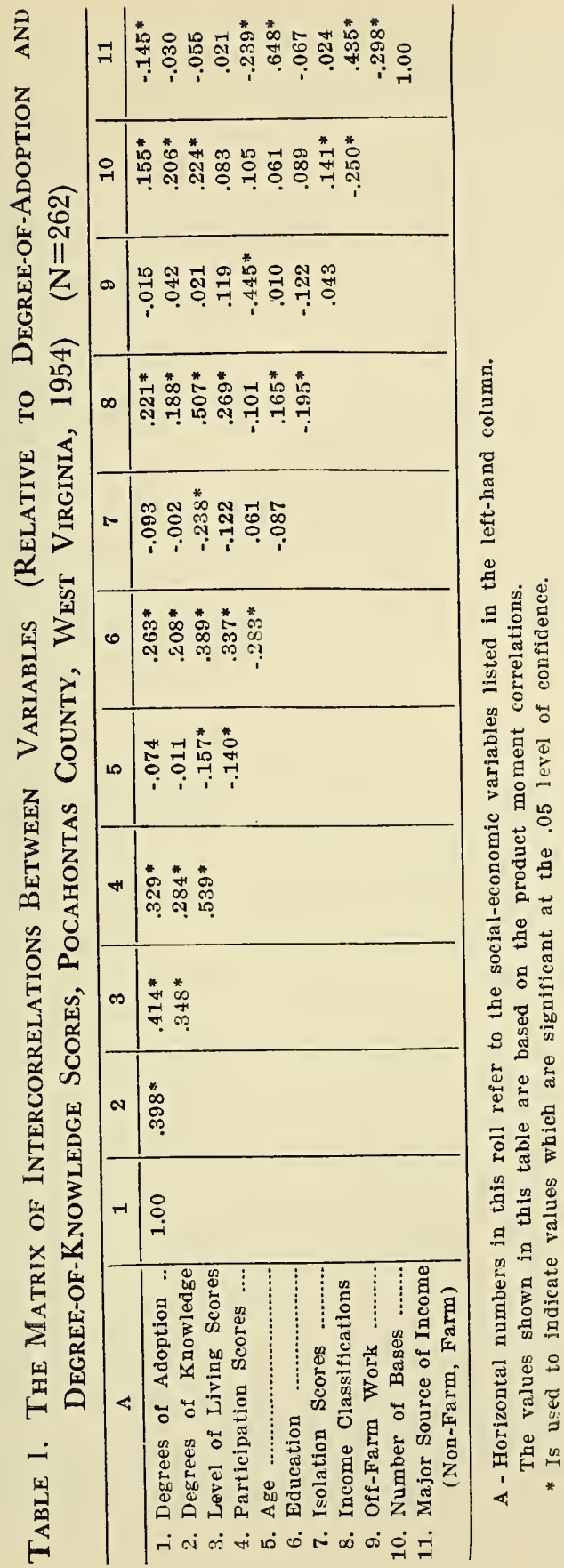


Table 2. Multiple and Partial Correlation Coefficients for

Degree-of-Adoption and Degree-of-Knowledge Scores and

Other Social Economic Variables

\begin{tabular}{|c|c|c|c|}
\hline$\hat{R}_{1.2346}$ & $=.5087$ & ${ }^{\mathrm{r}} 12.9$ & $=.399$ \\
\hline $\mathbf{R}_{1.234568}$ & $=.5095$ & ${ }^{r} 12.10$ & $=.379$ \\
\hline${ }^{\mathrm{r}} 12.3$ & $=.297$ & $r_{12.11}$ & $=.381$ \\
\hline$r_{12.4}$ & $=.336$ & ${ }^{r} 12.34$ & $=.285$ \\
\hline $\mathrm{r}_{12.5}$ & $=.398$ & ${ }^{r} 12.36$ & $=.290$ \\
\hline$r_{12.6}$ & $=.363$ & $r_{12.38}$ & $=.297$ \\
\hline${ }^{r} 12.7$ & $=.399$ & $\mathrm{r}_{12.3(11)}$ & $=.279$ \\
\hline${ }_{12.8}$ & $=.372$ & & \\
\hline
\end{tabular}

Subseripts in this table refer to the following variables:

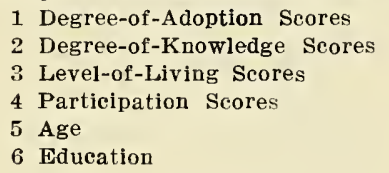

7 1solation Scores

8 Income Classifications

9 Off-Farm Work

10 Number of Bases

11 Major Sources of Income (Non-Farm, Farm)

The multiple correlation coefficients in Table 2 are higher than the product moment correlation of .398 indicated in Table 1. Despite the fact that a very highly significant statistical relationship exists, the size of the relationships between degree of adoption and other factors are not of a sufficient size as they have been isolated in this study so as to give any considerable predictive value.

In Pocahontas County, as well as in much of West Virginia, farm operations have certain characteristics which may affect motivation toward adoption and knowledge of recommended practices. Since the topography is rough, there are few localities where large acreages for field crops are available. Much of the farming is of a subsistence or low-income commercial type, and farm incomes frequently are supplemented by off-farm and non-work sources. On the basis of the sample, in Pocahontas County the median age of farm operators was 55, with 26 percent of the operators 65 years of age or over. The median education of the farm operators was grade eight, with 78 percent having completed no more than the eighth grade. Forty-three percent of the farm operators reported cash family incomes of less than. $\$ 1,000$, while 85 percent had incomes of less than $\$ 2,500$. Forty-five percent had greater non-farm than farm incomes; 28 percent worked more than 200 days off the farm; and 37 percent worked more than 100 days off the farm. 
These conditions undoubtedly affect both the motivation and the knowledge which operators have in respect to farm practices.

A study of the partial correlations relative to degree-of-adoption and degree-of-knowledge scores helps to clarify the relationship of the variables involved. Although many of the partial correlation coefficients exhibited in Table 2 do not suggest significant influences on the relationship between degrees of knowledge and adoption, there are several which approach significance. The factors which seem to lower the relationship are level of living and level of living in combination witl participation, education, income classification or major source of income. These data might be interpreted as follows: when the level of living is improved among these West Virginia farm operators, there is less tendency to apply their knowledge of farm practices to their farm operations. However, in these instances, the levels of living were improved through non-farm sources, and therefore interest in farming was probably recluced. This situation may be unique to agriculture conditions similar to those in West Virginia's low-income commercial agriculture and alternative off-farm job opportunities.

\section{Conclusions}

This study deals with the relationship between knowledge and adoption of farm practices as well as between knowledge and certain social-economic variables. The relationship found, although very highly significant statistically, had low predictive value, even when analyzed by multiple correlation techniques. The partial correlation coefficients suggest certain relationships which characterized the agriculture under study. Reference to social-economic data of the sample area seemed to explain the relationships which were brought out in the study.

The study of these relationships was made in an agricultural situation in which results of a high predictive level should perhaps not have been anticipated. With the use of a similar approach to the problem, research undertaken in an area in which the farm operators are engaged in an intensive commercial agriculture might discover a relationship of much higher predictive value.

Since we are being committed by our acceptance of technological developments and scientific knowledge to an increasingly complex system of agriculture, with sets of recommendations indicating specilic procedures, it would seem that this facet of diffusion research warrants increased attention from rural sociologists. 


\section{APPENDIX 1}

\section{Recent Publications Relating to Degree - of-Knowledge of Recommended Farm Practices}

Hoffer, Charles and Strangland, Dale, Farmers Reactions to New Practices. Michigan AES Technical Bulletin 264, February 1958.

Neilson, James and Bittner, R. F., Farm Practice Adoption in Michigan.

Michigan AES Technical Bulletin 263, January 1958.

Raudabaugh, J. Neil, A Study of the Cotton Production Improvement Programs in Nine Southern States. USDA Extension Service Circular 515, December 1957.

Raudabaugh, J. Neil and Cavender, John, Arkansas Extension Pilot Cotton Action Research Project. Unpublished Manuscript.

Sarbaugh, Lawrence E., Audience Inventory: A Guide to More Effective Communications. MS Thesis, University of Illinois, 1954.

Sorenson, Douglas, Factors Influencing Knowledge of Technical Soil Concepts by Wisconsin Farmers. Department of Agricultural Journalism, College of Agriculture, University of Wisconsin Bulletin 27, March 1957.

\section{APPENDIX 2}

\section{The Pattern of Questions in Securing Information About Pasture Practices. (Excerpt from interviewing schedule, "The Diffusion of Farm Practices")}

Now, Mr. ............., we picked out several different farm practices to talk with each farmer about. The first one on the list has to do with pastures.

21. How many acres did you have last year in permanent pasture? (acres)

(Omit next 4 questions if no permanent pasture.) 
22. (a) Do you mow your permanent pasture every year? (Check)

(1) All of $\ldots \ldots \ldots \ldots . . .6$.

(2) Some $\ldots \ldots \ldots \ldots \ldots \ldots$

(3) None $\ldots \ldots \ldots \ldots$

(Omit next 3 questions if answer above is "none".)

(b) How many times a year do you mow? (Check)

(1) Once ........

(2) Twice $\ldots \ldots$...

(3) Other (specify)

(c) Is there any special time when you usually mow your permanent pasture?

(Check 2 items if 2 mowings a year.)

(1) No special time .......

(4) After grass has gone

(2) Before grass is in to seed bloom ..............

(5) Before weeds go to seed ....

(3) When grass is in

(6) After weeds go to seed .... bloom

(7) Other (specify) $\ldots \ldots \ldots \ldots$.

(d) About how long have you been following this practice? (years).

23. Now, different farm groups and agencies have made certain recommendations on mowing permanent pasture. We'd like to find out whether farmers have heard about these recommendations, where they heard about them, and how they feel about them.

(a) Have you ever heard or read about the recommendations or received any information on mowing permanent pasture?

(1) Yes $\ldots \ldots \ldots$

(2) No $\ldots \ldots$.

(3) Not sure $\ldots \ldots \ldots$

(Omit next 6 questions if answer above is "no".)

(b) Do you remember what they were? (Check)

(1) Don't know ......

(4) Mow once a year .....

(2) Mow when bluegrass is

(5) 1 in spring and 1 in fall in bloom ......

(6) Other (Specify) .....

(3) Mow before weeds go to seed ......

(c) It may be hard to say when you first heard about the recommendations; but if you do remember, or can give us a rough idea, we'd like to know. ......... (year). 
(d) Now, farmers get information on recommended practices in many different ways. (A list of sources where a farmer might get information could include: friends, relatives, farm agencies and organizations, bulletins, newspapers, magazines, radio, and so on.) We know it may be hard to remember in some cases, but can you tell us where you got your first bit of information on this recommended practice? (Refer to check list and abbreviate source.)

(Six different randomized arrangements of the sources were used).

(e) From what other sources on that list have you gotten information on this recommended practice? (Include sources not on the list, if any.) (Abbreviate)

(f) From which of these sources did you get most of your information on this recommended practice? (Abbreviate)

(g) How do you feel about this recommended practice? (Write in answer.) Or can you think of any drawbacks? ............. 



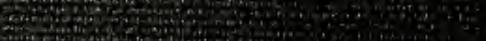

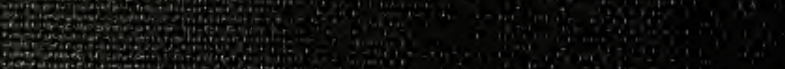

